\title{
Photoluminescence Electron-Transfer Quenching of Rhenium(I) Rectangles with Amines
}

\author{
P. Thanasekaran, ${ }^{\dagger}$ Rong-Tang Liao, ${ }^{\dagger}$ Bala. Manimaran, ${ }^{\dagger}$ Yen-Hsiang Liu, ${ }^{\dagger}$ Pi-Tai Chou,, \\ S. Rajagopal, ${ }^{\ddagger}$ and Kuang-Lieh Lu*,† \\ Institute of Chemistry, Academia Sinica, Taipei 115, Taiwan, Department of Chemistry, National Taiwan \\ University, Taipei 107, Taiwan, and School of Chemistry, Madurai Kamaraj University, Madurai 625021 , \\ India
}

Received: January 19, 2006; In Final Form: May 23, 2006

\begin{abstract}
Electron-transfer (ET) reactions from aromatic amines to excited states of rhenium(I)-based molecular rectangles $\left[\left\{\operatorname{Re}(\mathrm{CO})_{3}(\mu\right.\right.$-bpy $\left.) \mathrm{Br}\right\}\left\{\operatorname{Re}(\mathrm{CO})_{3}(\mu \text {-L) } \mathrm{Br}\}\right]_{2}$ (bpy = 4,4'-bipyridine, $\mathrm{L}=4,4^{\prime}$-dipyridylacetylene (dpa), $\mathbf{I} ; \mathrm{L}=$ 4,4'-dipyridylbutadiyne (dpb), II; and $\mathrm{L}=1,4$-bis(4'-pyridylethynyl)benzene (bpeb), III) were investigated in a dichloromethane solution using luminescence quenching techniques. Direct evidence for the ET reaction was obtained from the detection of the amine cation radical in this system using time-resolved transient absorption spectroscopy. The values of the luminescence quenching rate constants, $k_{\mathrm{q}}$, of the ${ }^{3}$ MLCT excited state of $\operatorname{Re}(\mathrm{I})$ rectangles with amines were found to be higher than those for the monomeric $\operatorname{Re}(\mathrm{I})$ complexes and other $\operatorname{Re}(\mathrm{I})$-based metallacyclophanes. The observed $k_{\mathrm{q}}$ values were correlated well with the driving force $\left(\Delta G^{\circ}\right)$ for the ET reactions. In addition, a semiclassical theory of ET was successfully applied to the photoluminescence quenching of $\operatorname{Re}(\mathrm{I})$ rectangles with amines.
\end{abstract}

\section{Introduction}

Amines are excellent electron donors because of their low ionization potentials. The lone pair electrons on the nitrogen atom leads to facile electron-transfer (ET) reactions of amines in a number of chemical, electrochemical, photochemical, and biochemical redox processes. ${ }^{1-3}$ The one-electron oxidation of amines leads to the formation of radical intermediates that can be used in the synthesis of amino acids, alkaloids, and several other nitrogen-containing compounds of biological and pharmaceutical importance. ${ }^{4}$ Electron-transfer reactions of amines are also important in certain technological applications such as imaging ${ }^{5}$ and photopolymerization, ${ }^{6}$ etc. In addition, the electrondonating capability of the amino functionality has been extensively used for designing new materials such as organic conductors, ${ }^{7}$ electroluminescent materials,${ }^{8}$ photovoltaics, ${ }^{9}$ and materials with nonlinear optical activity. ${ }^{10}$

The development of macrocycles in which ruthenium(II), osmium(II), and rhenium(I) metal centers are linked by spacers with a $\pi$ conjugation has gained importance in view of their potential applications in the emerging fields of molecular-scale electronics, sensors, and devices. ${ }^{11}$ An attractive pursuit in this area is the design of rigid building blocks with readily tunable electronic, steric, and photophysical characteristics. ${ }^{12}$ The unique nature of the metal-acetylide interaction permits the delocalization of electron density and has been used to advantage in several active areas of materials science. ${ }^{13}$ However, reports on Re-based rectangles containing acetylides appear to be relatively sparse. ${ }^{14}$ During the past decade $\operatorname{Re}(\mathrm{I})$ centers have played an important role as supramolecular components in generating welldefined architectures such as squares, rectangles, and so on. ${ }^{15}$ Furthermore, the special structural and spectroscopic charac-

\footnotetext{
* Corresponding author. Fax: +(2)27831237. E-mail: lu@ chem.sinica.edu.tw.

Academia Sinica.

$\S$ National Taiwan University.

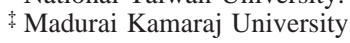

teristics of $\operatorname{Re}(\mathrm{I})$ complexes employed in the self-assembly process could permit functional properties such as Lewis acidity, luminescence, or redox activity to be introduced into the macrocyclic structure. These properties could be tuned by changing the coordinated or ancillary ligands. ${ }^{16-18}$ Although there has been much interest in the self-assembly of $\operatorname{Re}(\mathrm{I})$-based molecular rectangles, there are still relatively few studies on photoinduced electron-transfer reactions of the excited state of $\operatorname{Re}(\mathrm{I})$-based rectangles with electron donors and acceptors. ${ }^{19 \mathrm{a}}$

Hupp and co-workers ${ }^{19 a}$ reported that the emission quenching of a Re-based rectangle, $\left(\left[\left\{\operatorname{Re}(\mathrm{CO})_{3}(\mu\right.\right.\right.$-bpy $\left.)\right\}\left\{\operatorname{Re}(\mathrm{CO})_{3}(\mu\right.$-BiBzIm) $\}]_{2}$, bpy $=4,4^{\prime}$-bipyridine and BiBzIm = bisbenzimidazole), with quinones and amines is controlled by diffusionlimiting rates. Further, Lees' group ${ }^{19 b}$ reported that the luminescence of a $\operatorname{Re}(\mathrm{I})$-based square is effectively quenched by nitro-substituted aromatic compounds. Electron-transfer reaction of amines with monomeric $\operatorname{Re}(\mathrm{I})$ complexes and other electron acceptors in the excited state have also been studied by several research groups. ${ }^{20}$ Herein we report a detailed study on excited-state electron-transfer reactions of rhenium(I)-based molecular rectangles with a series of aromatic amines using steady-state and time-resolved fluorescence quenching measurements. The formation of an amine cation radical, the intermediate, was observed for the first time using the supramolecular $\operatorname{Re}(\mathrm{I})$ rectangle as a photosensitizer. The efficiency of the quenching rate constants, $k_{\mathrm{q}}$, is in good agreement with the free energy change $\left(\Delta G^{\circ}\right)$ for the ET reaction and is higher than that for monomeric $\operatorname{Re}(\mathrm{I})$ complexes and other $\operatorname{Re}(\mathrm{I})$-based metallacyclophanes. Semiclassical theory of ET was applied successfully for the first time in the photoluminescence quenching of $\operatorname{Re}(\mathrm{I})$ rectangles with aromatic amines.

\section{Experimental Section}

2.1. Materials. The rectangles $\left[\left\{\operatorname{Re}(\mathrm{CO})_{3}(\mu\right.\right.$-bpy $\left.) \mathrm{Br}\right\}\{\mathrm{Re}-$ $(\mathrm{CO})_{3}(\mu$-L)Br$\left.\}\right]_{2}\left(\mathrm{~L}=4,4^{\prime}\right.$-dipyridylacetylene (dpa), $\mathbf{I} ; \mathrm{L}=4,4^{\prime}$ dipyridylbutadiyne (dpb), II; and $\mathrm{L}=1,4$-bis(4'-pyridylethynyl)- 
CHART 1: Structures of Molecular Rectangles I-III
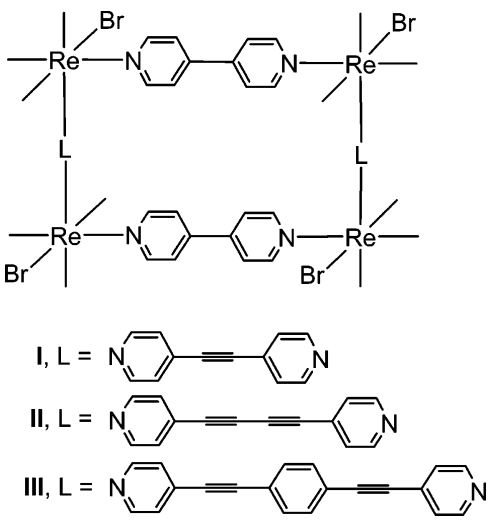

\section{CHART 2: Structures of Aromatic Amine Quenchers}<smiles>Nc1ccccc1</smiles><smiles>CCN(CC)c1ccccc1</smiles>

6<smiles>c1ccc(Nc2ccccc2)cc1</smiles>

2<smiles>COc1ccc(N)cc1</smiles>

7

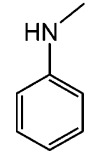

3

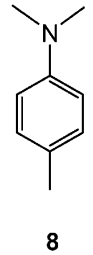

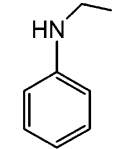

4

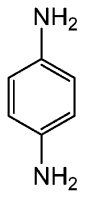

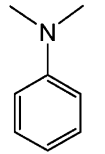

5

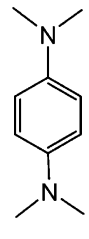

10 benzene (bpeb), III) used in the present study were synthesized by previously published procedures. ${ }^{14,21}$ All reactions and manipulations were carried out under $\mathrm{N}_{2}$ or Ar with the use of standard inert-atmosphere and Schlenk techniques. Aniline and its derivatives were obtained commercially and used without further purification. Tetrabutylammonium hexafluorophosphate was recrystallized from ethanol and vacuum-dried prior to use. Dichloromethane was of spectroscopy grade and used as received.

2.2. Equipment and Procedures. UV-vis absorption spectral measurements were made with a Hewlett-Packard 8453 spectrophotometer at room temperature. Steady-state luminescence measurements were carried out with a Hitachi fluorescence F-4500 spectrophotometer. In a typical experiment, the deaerated sample solution was prepared in a $1 \mathrm{~cm} \times 1 \mathrm{~cm}$ quartz fluorescence cell. The concentrations of $\mathbf{I}-$ III were maintained at $(5-8) \times 10^{-5} \mathrm{M}$ in all samples, and the quencher concentrations were between $1 \times 10^{-4}$ and $1 \times 10^{-2} \mathrm{M}$. The excitation wavelength for luminescence experiments was 351-357 nm and for lifetime experiments was $355 \mathrm{~nm}$. The luminescence spectrum of each sample was measured, and the relative emission yields were determined as a function of quencher concentration. Intensities were recorded for at least five different concentrations of each quencher. Selected emission quenching experiments were also followed by lifetime measurements. Specifically, the emission lifetime was monitored as a function of quencher concentration. For each experiment, the first measurement involved the emission lifetime without a quencher present, $\tau_{\mathrm{o}}$. The values of $\tau_{\mathrm{o}}$ for $\mathbf{I}-$ III were recorded in all
TABLE 1: Absorption and Emission Maxima, Excited-State Lifetime, and Redox Potentials of Rhenium(I)-Based Molecular Rectangles in $\mathrm{CH}_{2} \mathrm{Cl}_{2}$ at $298 \mathrm{~K}$

\begin{tabular}{ccccc}
\hline rectangle & $\lambda_{\max }{ }^{\mathrm{ab}}, \mathrm{nm}$ & $\lambda_{\max }{ }^{\mathrm{em}}, \mathrm{nm}$ & $\tau, \mathrm{ns}$ & $E^{\mathrm{o}(+* / 0)}{ }^{a} \mathrm{~V}$ \\
\hline I & 352 & 611 & 86 & 1.11 \\
II & 357 & 616 & 72 & 0.82 \\
III & 351 & 616 & 495 & 0.91
\end{tabular}

${ }^{a}$ Excited-state potential of $\operatorname{Re}(\mathrm{I})$-based molecular rectangles is calculated from $E_{\mathrm{oo}}$ and ground-state potentials in dichloromethane.

experiments and were subsequently used to determine $k_{\mathrm{q}}$ from the slopes of the Stern-Volmer plots.

Electrochemical measurements were performed on a BAS 100B/W EC workstation. The electrochemical cell consisted of a glassy carbon working electrode, a platinum wire counter electrode, and a $\mathrm{Ag} / \mathrm{AgNO}_{3}\left(0.01 \mathrm{M}\right.$ in $\left.\mathrm{CH}_{3} \mathrm{CN}\right)$ reference electrode. Cyclic and differential pulse voltammograms were obtained in deoxygenated $\mathrm{CH}_{2} \mathrm{Cl}_{2}$ with the electrode-active materials $\left(1 \times 10^{-3} \mathrm{M}\right)$ and $0.1 \mathrm{M}$ tetra- $n$-butylammonium perchlorate (TBAP) as the supporting electrolyte. The scan rate was $100 \mathrm{mV} / \mathrm{s}$ unless otherwise stated.

The excited-state lifetimes of all rectangles in $\mathrm{CH}_{2} \mathrm{Cl}_{2}$ were measured using a time-correlated single photon counting $\mathrm{FL}$ 920 nanosecond spectrometer (Edinburgh Instrument). The sample solutions were carefully purged with dry nitrogen for $30 \mathrm{~min}$ to ensure that there was no change in the volume of the solution. The flash photolysis apparatus for the study of transient absorption spectra in the nanosecond time domain has been described elsewhere. ${ }^{22}$ The excitation wavelength of $355 \mathrm{~nm}$ from a Nd:YAG laser (Continuum Surlite II, third harmonic) was used as the excitation source, coupled with a fast response photomultiplier (Hamamatsu model R5509-72) operated at -80 ${ }^{\circ} \mathrm{C}$ in the nanosecond flash photolysis experiments (pulse width, ca. $8 \mathrm{~ns}$; energy, $50 \mathrm{~mJ} /$ pulse). Transient spectra were obtained by a point-to-point technique, monitoring the absorbance changes $(\Delta A)$ after the flash at intervals of $10 \mathrm{~nm}$ over the spectral range of 300-700 nm, averaging at least 30 decays at each wavelength. The values $\left(t_{1 / 2}\right.$, the time at which the initial signal is halved) are reported for transients showing secondorder kinetics. The transient absorption signal was recorded by a laser flash photolysis system (Edinburgh LP 920), in which a Nd:YAG laser $(355 \mathrm{~nm})$ pumped optical parametric oscillator and a white-light square pulse were used as the pump and probe beams, respectively. The temporal resolution was limited by the excitation pulse duration of $\sim 8 \mathrm{~ns}$.

\section{Results and Discussion}

3.1. Spectral Studies. The structures of the $\operatorname{Re}(\mathrm{I})$-based rectangles $\left[\left\{\operatorname{Re}(\mathrm{CO})_{3}(\mu\right.\right.$-bpy $\left.) \mathrm{Br}\right\}\left\{\operatorname{Re}(\mathrm{CO})_{3}(\mu \text {-L)Br}\}\right]_{2}$ and aromatic amines used in the present study are shown in Charts 1 and 2, respectively. Table 1 summarizes the electronic absorption and emission spectral data, excited-state lifetime, and excited-state redox potential data for rectangles I-III. The Re(I)-based molecular rectangles I-III display an intense absorption band at $351-357 \mathrm{~nm}$ and a luminescence at $611-616 \mathrm{~nm}$ in dichloromethane at room temperature. The intense absorption of I-III at 351-357 $\mathrm{nm}$ has been assigned to a spin-allowed metal-ligand charge-transfer (MLCT) transition from the Re metal d orbital to the $\pi^{*}$ orbital of the ligand. The origin of the emission from the $d-\pi^{*}$ states in $\operatorname{Re}(\mathrm{I})$-based rectangles is the ${ }^{3}$ MLCT state. ${ }^{23}$ The preliminary studies on the photophysical properties of I-III have been reported in our previous paper. ${ }^{14}$

To check the ground-state complex formation between Re(I)-based rectangles I-III and amines, we recorded the absorp- 
TABLE 2: Bimolecular Rate Constants ${ }^{a}$ for the Quenching of the ${ }^{3}$ MLCT Excited States of Rhenium(I)-Based Molecular Rectangles with Aromatic Amines in $\mathrm{CH}_{2} \mathrm{Cl}_{2}$ at $298 \mathrm{~K}$

\begin{tabular}{|c|c|c|c|c|c|c|c|}
\hline \multirow[b]{2}{*}{ no. } & \multirow[b]{2}{*}{ quencher $\left(E_{\text {oxd }}^{\circ}, \mathrm{V}\right)^{b}$} & \multicolumn{2}{|c|}{ I, $E^{+* / 0}=1.11 \mathrm{~V}$} & \multicolumn{2}{|c|}{ II, $E^{+* / 0}=0.82 \mathrm{~V}$} & \multicolumn{2}{|c|}{ III, $E^{+* / 0}=0.91 \mathrm{~V}$} \\
\hline & & $-\Delta G^{\circ}$ & $10^{-9} k_{\mathrm{q}}$ & $-\Delta G^{\circ}$ & $10^{-9} k_{\mathrm{q}}$ & $-\Delta G^{\circ}$ & $10^{-9} k_{\mathrm{q}}$ \\
\hline 1 & aniline $(0.93)$ & 0.18 & 0.76 & -0.11 & 1.0 & -0.02 & 0.15 \\
\hline 2 & diphenylamine $(0.83)$ & 0.28 & 6.0 & -0.01 & 4.9 & 0.08 & 0.96 \\
\hline 3 & $N$-methylaniline $(0.77)$ & 0.34 & $\begin{array}{c}5.7 \\
(5.3)\end{array}$ & 0.05 & 8.8 & 0.14 & 2.6 \\
\hline 4 & $N$-ethylaniline $(0.80)$ & 0.31 & 5.3 & 0.02 & 8.0 & 0.11 & 1.1 \\
\hline 5 & $N, N$-dimethylaniline $(0.81)$ & 0.30 & $\begin{array}{c}8.2 \\
(8.2)\end{array}$ & 0.01 & $\begin{array}{c}12.0 \\
(18.0)\end{array}$ & 0.10 & $\begin{array}{c}6.3 \\
(6.2)\end{array}$ \\
\hline 6 & $N, N$-diethylaniline $(0.76)$ & 0.35 & 8.1 & 0.06 & 15.0 & 0.15 & 5.6 \\
\hline 7 & $p$-anisidine $(0.71)$ & 0.40 & 7.2 & 0.11 & 8.7 & 0.20 & 1.0 \\
\hline 8 & $N, N$-dimethyl- $p$-toluidine $(0.71)$ & 0.40 & 9.5 & 0.11 & 7.8 & 0.20 & 9.7 \\
\hline 9 & $p$-phenylenediamine $(0.18)$ & 0.93 & 20.0 & 0.64 & 22.0 & 0.73 & 21.0 \\
\hline 10 & $N, N, N^{\prime}, N^{\prime}$-tetramethylphenylenediamine $(0.12)$ & 0.99 & $\begin{array}{c}46.0 \\
(11.0)\end{array}$ & 0.70 & $\begin{array}{c}56.0 \\
(15.0)\end{array}$ & 0.79 & $\begin{array}{l}14.0 \\
(9.6)\end{array}$ \\
\hline
\end{tabular}

${ }^{a}$ Within $10 \%$ error, the $k_{\mathrm{q}}$ values given in parentheses are taken from lifetime quenching measurements. ${ }^{b}$ Ref 25.

tion spectra of a mixture of a rectangle and an amine using concentrations of reactants similar to those used in the quenching studies. No evidence was obtained for ground-state complex formation between I-III and the amines, although $\mathbf{1 0}$ is an exception, based on absorption spectral studies. From the redox potential data shown in Table 1, the values of Gibbs free energy change, $\Delta G^{\circ}$, for the photoinduced ET reaction between the excited state of I-III and amines have been calculated (vide infra) and are given in Table 2 . The $\Delta G^{\circ}$ data given in Table 2 indicate that all the reactions are exoergic and may proceed at rates close to the diffusion-controlled rate if the reaction were controlled by exoergicity alone. The quenching rate constants of I-III with amines are dependent on the free energy change $\left(\Delta G^{\circ}\right)$. Similar trends in $\operatorname{Re}(\mathrm{I})$ molecular squares with aromatic nitro compounds have been reported by Lees and co-workers. ${ }^{19 b}$

3.2. Stern-Volmer Analysis. The emission intensities (I) as well as excited-state lifetimes $(\tau)$ of the $\operatorname{Re}(\mathrm{I})$-based rectangles I-III are efficiently quenched in the presence of amines in $\mathrm{CH}_{2}$ $\mathrm{Cl}_{2}$ and are analyzed in terms of the Stern-Volmer (SV) relationship,

$$
I_{\mathrm{o}} / I \text { or } \tau_{\mathrm{o}} / \tau=1+K_{\mathrm{sv}}[\mathrm{Q}]=1+k_{\mathrm{q}} \tau_{\mathrm{o}}[\mathrm{Q}]
$$

where $I_{\mathrm{o}}$ and $I$ are the emission intensities and $\tau_{\mathrm{o}}$ and $\tau$ are the excited-state lifetimes of I-III in the absence and presence of amines, respectively, while [Q] represents the concentration of amines. $K_{\mathrm{sv}}$ is the Stern-Volmer constant, and $k_{\mathrm{q}}$, the bimolecular quenching rate constant. Linear Stern-Volmer plots of $I_{\mathrm{o}} / I$ were observed for the amine quenchers except quencher 10. Plots of $\tau_{\mathrm{o}} / \tau$ vs [Q] were also linear for all quenchers and gave results that were in good agreement with the luminescence intensity quenching. ${ }^{24}$ However, at high concentration of quencher 10 the plot of $I_{\mathrm{o}} / I$ vs [Q] produces an upward curvature in the Stern-Volmer plot ${ }^{27}$ with rectangles I-III with a blue shift in the emission maximum of the rectangle to $608 \mathrm{~nm}$ (Figure 1). This indicates that binding takes place between the rectangle and quencher $\mathbf{1 0}$, resulting in more efficient quenching. To explain the nonlinearity of the curve, the extended SternVolmer equation (eq 2) was used

$$
I_{o} / I=\left(1+K_{\mathrm{D}}[\mathrm{Q}]\right)\left(1+K_{\mathrm{S}}[\mathrm{Q}]\right)
$$

where $K_{\mathrm{D}}$ and $K_{\mathrm{S}}$ are the dynamic and static Stern-Volmer constants, respectively. A typical Stern-Volmer plot for the reductive quenching of I with $N, N, N^{\prime}, N^{\prime}$-tetramethylphenylenediamine obtained from steady-state and time-resolved measurements is shown in Figure 2. A nonlinear $I_{\mathrm{o}} / I$ vs [Q] plot for

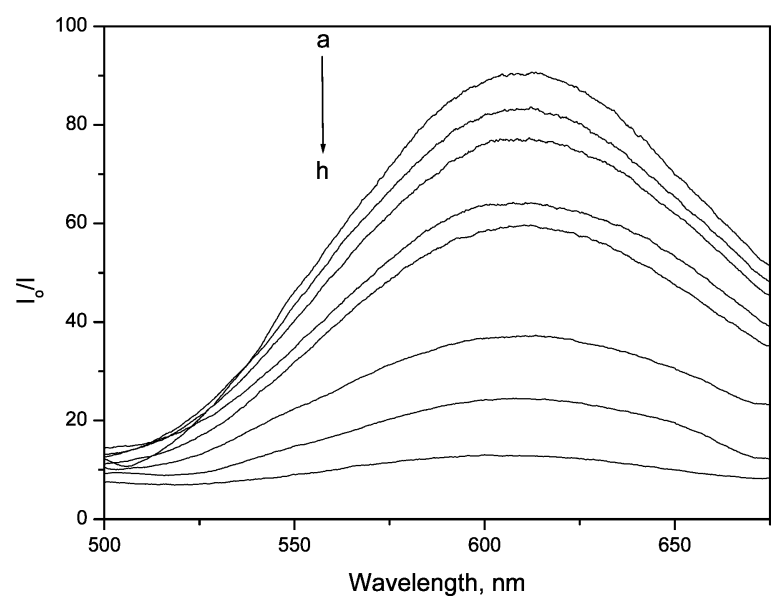

Figure 1. Luminescence intensity quenching of rectangle I with quencher 10 in the concentration range of (a) 0 , (b) $2 \times 10^{-5}$, (c) $4 \times$ $10^{-5}$, (d) $6 \times 10^{-5}$, (e) $10 \times 10^{-5}$, (f) $12 \times 10^{-5}$, (g) $18 \times 10^{-5}$, and (h) $24 \times 10^{-5} \mathrm{M}$ in dichloromethane.

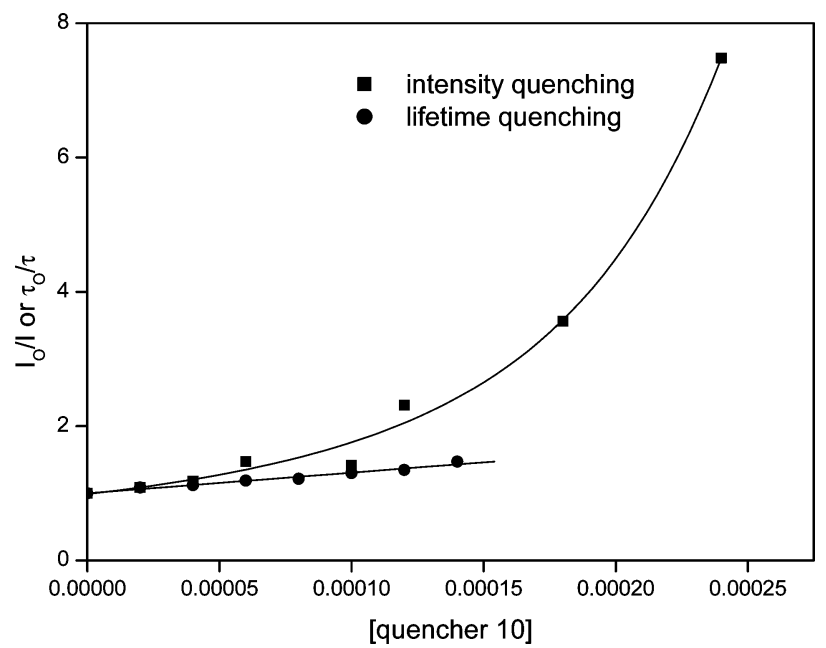

Figure 2. Stern-Volmer plot for the reductive quenching of rectangle I with different concentrations of quencher $\mathbf{1 0}$ in dichloromethane.

quencher 10 shown in Figure 2 suggests the presence of a static component in the quenching process along with dynamic quenching.

The $k_{\mathrm{q}}$ values obtained from steady-state and time-resolved techniques suggest that the quenching of rectangles with amines is dynamic in nature, except for quencher $\mathbf{1 0}$ (Table 2). The emission quenching of rhenium(I)-based molecular rectangles 
SCHEME 1: Photoinduced Electron-Transfer Mechanism of Luminescence Quenching of $\operatorname{Re}(\mathrm{I})$ Molecular Rectangles I-III with Aromatic Amines

$$
\begin{aligned}
& { }^{*} \mathrm{Re}^{+}+\mathrm{Am} \quad \stackrel{\mathrm{k}_{12}}{\underset{\mathrm{k}_{21}}{\rightleftharpoons}} \quad\left[{ }^{*} \mathrm{Re}^{+} \ldots \mathrm{Am}\right] \quad \stackrel{\mathrm{k}_{-32}}{\stackrel{\mathrm{k}_{23}}{\rightleftharpoons}}\left[\mathrm{Re}^{0} \ldots \mathrm{Am}^{+}\right] \\
& \mathrm{hv} \| 1 / \tau \\
& \mathrm{Re}^{+}+\mathrm{Am} \longleftarrow \quad\left[\mathrm{Re}^{+} \ldots \mathrm{Am}\right]
\end{aligned}
$$
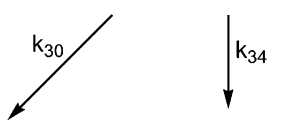

I-III by amines may be explained by a number of possible mechanisms such as electron-transfer, energy-transfer, or protoncoupled electron-transfer reactions. Since the triplet energy of aromatic amines $(3.1 \mathrm{eV})^{26}$ is above the available excitation energy of the rhenium(I)-based molecular rectangles $(2.3 \mathrm{eV})$, electronic energy transfer is less probable here. A mechanism involving proton transfer from amines to I-III can also be excluded because $N, N$-disubstituted anilines also effectively quench the luminescence of rhenium(I) rectangles. The results of both steady-state and time-resolved experiments indicate that the effect of aromatic amines on the luminescence of the $\operatorname{Re}(\mathrm{I})$ rectangles must be associated with only a dynamic quenching process through ET (Scheme 1). Wrighton and co-workers ${ }^{27}$ demonstrated the luminescence quenching of a monomeric Re(I) complex with a different energy level of quenchers. Since the triplet energy of anthracene is below the energy of the Re(I) triplet state, anthracene quenches through energy transfer at nearly a diffusion-controlled rate. When trans-stilbene is used as a quencher, its triplet energy is isoenergetic with the $\operatorname{Re}(\mathrm{I})$ complex and, as a result, it quenches much more slowly via triplet-triplet energy transfer. It has already been shown by various groups ${ }^{28}$ that the ${ }^{3} \mathrm{MLCT}$ excited state of monomeric $\operatorname{Re}(\mathrm{I})$ - polypyridyl complexes is readily quenched by a variety of electron donors through an ET mechanism. Compared to the monomeric $\operatorname{Re}(\mathrm{I})$ complexes, the efficiency of the quenching $\left(k_{\mathrm{q}}\right)$ of $\operatorname{Re}(\mathrm{I})$ containing molecular rectangles $\mathbf{I}-$ III with amines is found to be higher (Table 2), i.e., one order higher in $k_{\mathrm{q}}$ values than the monomeric $\operatorname{Re}(\mathrm{I})$ complexes. ${ }^{20 \mathrm{a}, 28 \mathrm{a}}$ To better understand the nature of the quenching process, it is appropriate to correlate the bimolecular quenching rate constants with the free energy change of the ET process. The values of $\Delta G^{\circ}$ were calculated from the excited-state reduction potentials of $\operatorname{Re}(\mathrm{I})$ complexes and the oxidation potentials of the amines (vide infra). It is apparent from the data in Table 2 that amines with lower oxidation potentials exhibit higher quenching rate constants, a

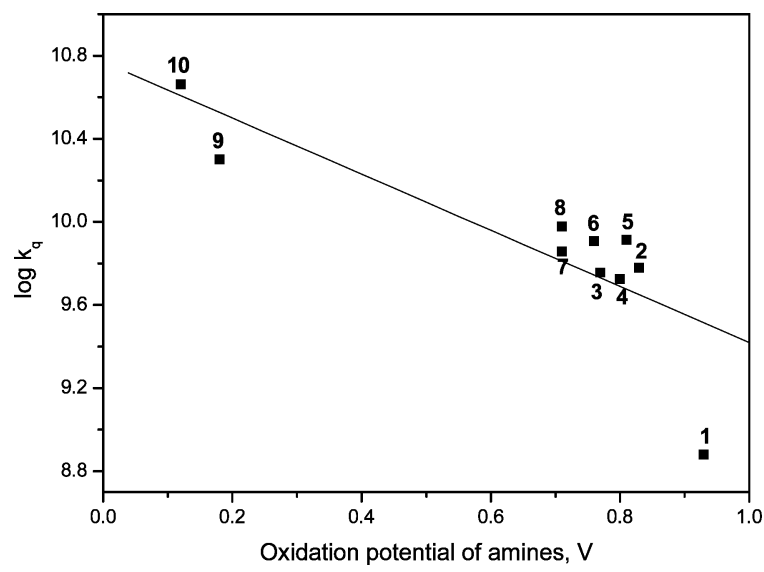

Figure 3. Plot of $\log k_{\mathrm{q}}$ vs the oxidation potential of aromatic amines for the oxidation of amines by rectangle $\mathbf{I}$.

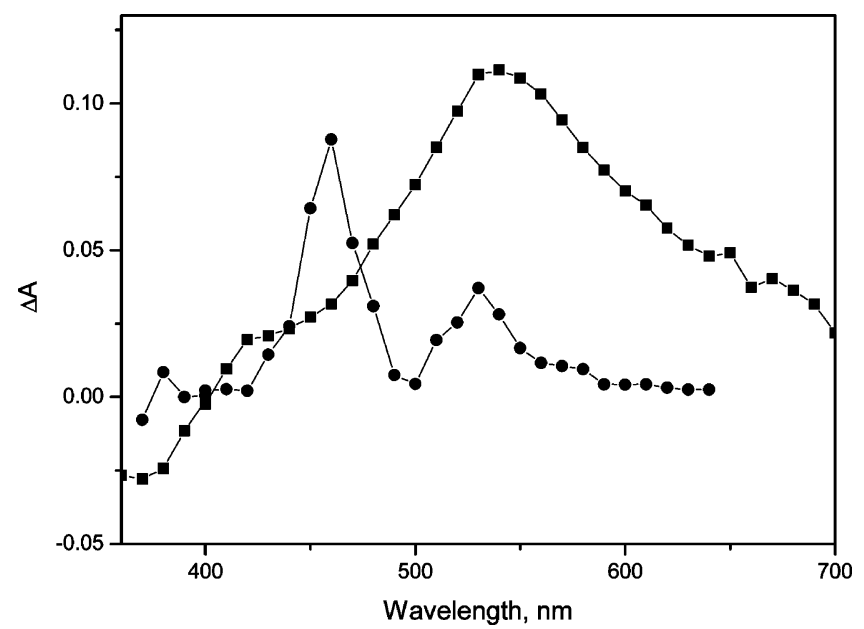

Figure 4. Transient absorption spectra obtained by laser flash photolysis of (a) $\operatorname{Re}(\mathrm{I})$ rectangle III (ם) and (b) III in the presence of $N, N$-diethylaniline (๑) in dichloromethane, recorded following $355 \mathrm{~nm}$ laser pulse excitation.

trend that is indicative of electron-transfer quenching. In addition, the plot of $\log k_{\mathrm{q}}$ vs oxidation potentials of aromatic amines is linear (Figure 3), which provides additional support for the electron-transfer mechanism. The validity of an electrontransfer quenching mechanism derives further support from a study of transients using flash-photolysis technique.

3.3. Transient Absorption Studies. Monochromatic flash irradiation of III in $\mathrm{CH}_{2} \mathrm{Cl}_{2}$ was used to perform the transient absorption spectral measurement. The broad, featureless transient absorption band of III at 400-700 nm was tentatively assigned to the reduced species of an $\operatorname{Re}(\mathrm{I})$ rectangle (Figure 4). Meyer and co-workers have already reported that an intense absorption at $450-600 \mathrm{~nm}$ is characteristic of a $4,4^{\prime}$-bpy-localized MLCT excited state in an $\operatorname{Re}(\mathrm{I})$ complex. ${ }^{29}$ The emission decay of III at $540 \mathrm{~nm}$ can be fitted without appreciable deviation, to a single exponential.

To gain more insight into the nature of the quenching process, the reaction of the long-lived excited state of $\operatorname{Re}(\mathrm{I})$ rectangle III with $N, N$-diethylaniline was carried out using laser timeresolved absorption studies by means of $8 \mathrm{~ns}$ laser width at 355 $\mathrm{nm}$ excitation. In accordance with the well-known excited-state absorption of the $\mathrm{N}, \mathrm{N}$-diethylaniline cation radical, ${ }^{30}$ an absorption band maximum at $470 \mathrm{~nm}$ occurred when $N, N$-diethylaniline quenches the luminescence of rectangle III. The transient absorption decay spectrum observed at $470 \mathrm{~nm}$ following the irradiation of $\operatorname{Re}(\mathrm{I})$ rectangle III $\left(8 \times 10^{-4} \mathrm{M}\right)$ with $\mathrm{N}, \mathrm{N}$ diethylaniline $(0.04 \mathrm{M})$ in dichloromethane is shown in Figure 4. Quenching of the luminescence of monomeric $\operatorname{Re}(\mathrm{I})$ complexes, concurrent with the observation of a transient oneelectron reduction product, $\operatorname{Re}(0)$, has been previously observed for several amines. ${ }^{28}$ The formation of an amine radical was observed for the first time in the ${ }^{3}$ MLCT excited-state electrontransfer reaction of $\operatorname{Re}(\mathrm{I})$ rectangle with an amine. Thus it is clear that, in the presence of $N, N$-diethylaniline, the triplet-state MLCT of $\operatorname{Re}(\mathrm{I})$ rectangle III in dichloromethane is efficiently quenched by the transfer of an electron from $N, N$-diethylaniline to form the reduced species of the $\operatorname{Re}(\mathrm{I})$ rectangle and a radical cation of $\mathrm{N}, \mathrm{N}$-diethylaniline.

3.4. Application of Theory of ET. After establishing the electron-transfer nature of the quenching process, we applied the semiclassical theory of ET (eq 3) to the rectangle-amine redox system. 


$$
\begin{aligned}
k_{\mathrm{et}}= & 4 \pi^{2} / h\left|H_{\mathrm{DA}}\right|^{2}\left(4 \pi \lambda_{\mathrm{o}} k T\right)^{-1 / 2} \\
& \sum_{m=0}^{\infty}\left(\mathrm{e}^{-S} S^{m} / m !\right) \exp \left[-\left(\lambda_{\mathrm{o}}+\Delta G^{\circ}+m h v\right)^{2} / 4 \lambda_{\mathrm{o}} k T\right]
\end{aligned}
$$

where $H_{\mathrm{DA}}$ is the electronic coupling coefficient between the redox centers, the reorganization energy $\lambda$ is composed of solvational $\lambda_{\mathrm{o}}$ and vibrational $\lambda_{\mathrm{i}}$ contributions with $\mathrm{s}=\lambda_{\mathrm{i}} / h v, v$ is the high-energy vibrational frequency associated with the acceptor, and $m$ is the density of product vibrational levels. The terms $h$ and $k$ are Planck's and Boltzmann's constants, respectively.

The value of $\lambda_{\mathrm{o}}$ can be evaluated classically by using the dielectric continuum model,

$$
\lambda_{\mathrm{o}}=e^{2} / 4 \pi \epsilon_{\mathrm{o}}\left(1 / 2 r_{\mathrm{D}}+1 / 2 r_{\mathrm{A}}-1 / d\right)\left(1 / D_{\mathrm{op}}-1 / D_{\mathrm{s}}\right)
$$

where $e$ is the transferred electronic charge, $\epsilon_{\mathrm{o}}$ is the permittivity of free space, and $D_{\mathrm{op}}$ and $D_{\mathrm{s}}$ are the optical and static dielectric constants, respectively. The terms $r_{\mathrm{D}}$ and $r_{\mathrm{A}}$ are the radii of the electron donor and acceptor, respectively, and $d$ is the separation distance between the donor and acceptor in the encounter complex. The values of $r_{\mathrm{D}}$ and $r_{\mathrm{A}}$ are estimated by the MM2 molecular model. The value of $\lambda_{\mathrm{o}}$ estimated from eq 4 falls in the range of $0.38-0.64 \mathrm{eV}$ for this redox system.

According to Rehm and Weller, the free-energy change of electron transfer can be calculated from ${ }^{31}$

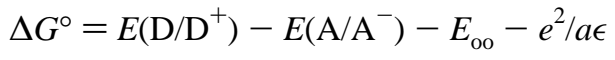

where $E\left(\mathrm{D} / \mathrm{D}^{+}\right)$is the oxidation potential of donors (amines), $E\left(\mathrm{~A} / \mathrm{A}^{-}\right)$the reduction potential of $\operatorname{Re}(\mathrm{I})$ containing rectangles I-III, $E_{\mathrm{oo}}$ the lowest excited-state energy of $\operatorname{Re}(\mathrm{I})$ rectangles, and $e^{2} / a \epsilon$ a columbic term. The $\Delta G^{\circ}$ values thus estimated for different rectangle and aniline pairs in dichloromethane are listed in Table 2.

Since it is established that the quenching occurs via ET, the redox quenching process, as shown in Scheme 1, can be discussed. According to Scheme 1, the excited-state acceptor $\left(* \mathrm{Re}^{\mathrm{I}}\right)$ and the ground-state donor (Am) molecules diffuse together to form an encounter complex $\left(* \operatorname{Re}^{\mathrm{I}} \cdots\right.$ Am). This encounter complex then undergoes a reorganization to reach the transition state where ET takes place from the donor to the acceptor to give an ion-pair species $\left(\operatorname{Re}^{0} \cdots \mathrm{Am}^{+} \bullet\right)$. The parameters $k_{12}$ and $k_{21}$ are the diffusion-controlled rate constants for the formation and dissociation of the encounter complex $* \operatorname{Re}^{\mathrm{I}}$ -.AAm, respectively. $k_{23}$ and $k_{32}$ are the forward and reverse ET rate constants, and $k_{34}$ is the sum of all the rate constants causing the disappearance of the ion-pair state $\left(\operatorname{Re}^{0} \cdots \mathrm{Am}^{+\bullet}\right)$.

By applying steady-state treatments to the short-lived species in Scheme 1, the following expression (eq 6) for the observed bimolecular quenching rate constant, $k_{\mathrm{obs}}\left(k_{\mathrm{q}}\right)$ can be derived.

$$
k_{\mathrm{obs}}=\frac{k_{12}}{1+\left(k_{12} / k_{23} K_{\mathrm{eq}}\right)}
$$

$K_{\text {eq }}$ is the equilibrium constant for the formation of the encounter complex, and $k_{12}$ is the rate constant for the diffusion process to form the encounter complex. The value of $k_{12}$ is calculated from $^{32}$

$$
k_{12}=2 R T / 3000 \eta\left[2+r_{\mathrm{D}} / r_{\mathrm{A}}+r_{\mathrm{A}} / r_{\mathrm{D}}\right] f
$$

where $f^{-1}=\mathrm{d} \int \mathrm{e}^{u} / k T \mathrm{~d} r / r^{2}$ with $u=Z_{\mathrm{D}} Z_{\mathrm{A}} e^{2} / D_{\mathrm{S}}\left[\mathrm{e}^{K d} / 1+K d\right]-$

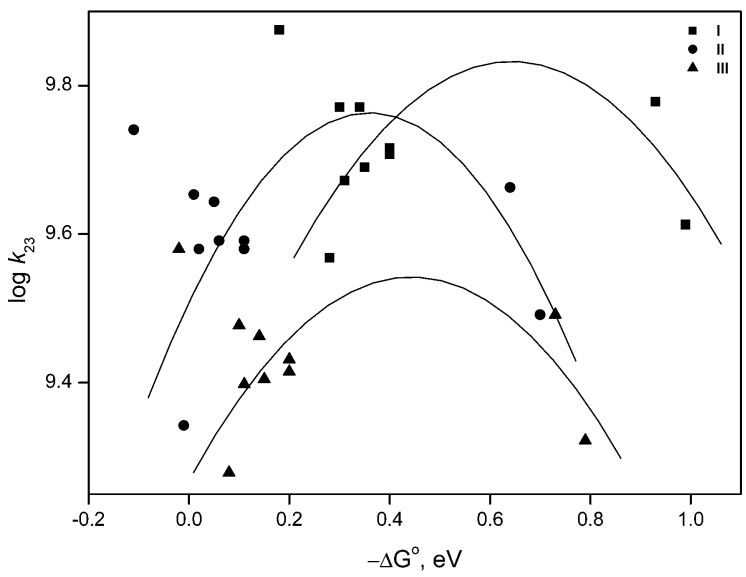

Figure 5. Plot of $\log k_{23}$ vs $-\Delta G^{\circ}$ for the $\operatorname{Re}(\mathrm{I})-$ amine system in dichloromethane. The points represent the experimental data, and the solid line curve is the best fit of the experimental rate constant data using semiclassical theory of ET (eq 3).

$\mathrm{e}^{-K r} / r$, where $K=\left(8 \pi \mathrm{e}^{2} N \eta / 1000 D_{\mathrm{S}} k T\right)^{1 / 2}, r_{\mathrm{D}}$ and $r_{\mathrm{A}}$ are the radii of the reactants, and $\eta$ is the viscosity of the medium.

The diffusion rate constant, $k_{12}$, calculated according to Smoluchowski ${ }^{32}$ for noncharged molecules, has a value of 2.3 $\times 10^{10} \mathrm{dm}^{3} \mathrm{~mol}^{-1} \mathrm{~s}^{-1} . K_{\text {eq }}$ was estimated using the Fuoss and Eigen equation ${ }^{33}$

$$
K_{\text {eq }}=\left(4 \pi N d^{3} / 3000\right) \exp \left(-w^{\mathrm{r}} / R T\right)
$$

where $w^{\mathrm{r}}$ is the work required to bring the reactants to the separation distance $d$. Since we use neutral quenchers throughout this study, $w^{\mathrm{r}}$ is zero. The value of $K_{\text {eq }}$ is found to be in the range of 2.52-9.28 $\mathrm{M}^{-1}$ for the reductive quenching of rectangles $\mathbf{I}-$ III with amines. Since the values of $k_{12}$ and $K_{\text {eq }}$ are known, the value for $k_{23}$, the rate constant for the process of ET in the encounter complex, can be calculated using eq 6, and the values are plotted against $\Delta G^{\circ}$ in Figure 5 for all three $\operatorname{Re}(\mathrm{I})$-containing rectangles $\mathbf{I}-\mathbf{I I I}$. The plot shows that the rate constant values for ET process calculated from Marcus theory are close to the experimental values. In eq $3, H_{\mathrm{DA}}=4.96 \times$ $10^{-3} \mathrm{eV}, \lambda=0.9 \mathrm{eV}, v=1000-1500 \mathrm{~cm}^{-1}$, and $T=298 \mathrm{~K}$. These values are the optimum values for the reaction, chosen by a trial and error method. ${ }^{34}$ Using eqs 3 and 6 , the rate constants, $k_{23}$, for the excited-state ET reaction of I-III with amines have been calculated. The experimental $k_{23}$ values along with the calculated $k_{\text {et }}$ values were plotted against $-\Delta G^{\circ}$ values (Figure 5) for all three $\operatorname{Re}(\mathrm{I})$ rectangles. The solid line curve in Figure 5 is a best fit of all of the rate constant data to the semiclassical equation (eq 3). Thus, the semiclassical theory of ET reproduces the experimental results favorably.

A careful analysis of the $k_{\mathrm{q}}$ data in Table 2 reveals that the quenching rate constants are influenced by the introduction of acetylene and phenyl moieties to the ligands and by the substituents in the aromatic amines as well. The $k_{\mathrm{q}}$ values determined from emission intensity data, particularly for rectangles I and II, appear to follow the trend of the lifetime quenching $k_{\mathrm{q}}$ values except for 10. Interestingly the $k_{\mathrm{q}}$ values obtained for III were consistently smaller than those obtained for I and II, indicating the importance of steric effect in this ET reaction. Concerning the quencher $N, N, N^{\prime}, N^{\prime}$-tetramethylphenylene diamine (10), the $k_{\mathrm{q}}$ value obtained from the luminescence intensity quenching of $\mathbf{I}-\mathbf{I I I}$ is high compared to the values obtained for lifetime quenching. This suggests the contribution by static quenching. Since the size of quencher $\mathbf{1 0}$ is large, there is a chance that the quencher may bind to the 
$\operatorname{Re}(\mathrm{I})$ rectangle. It would be of interest to compare the intensity and lifetime $k_{\mathrm{q}}$ values of $\mathbf{1 0}$ with rectangles I-III. Although the difference is large in the case of $\mathbf{I}$ and $\mathbf{I I}$, it is moderate for III. Rectangles I and II appear to be better hosts for $\mathbf{1 0}$ because of the suitable cavity size of rectangles I and II, although rectangle III has the largest cavity among the compounds. This leads to the binding of the quencher with the sensitizer, and, thus, a significant difference between the intensity and lifetime $k_{\mathrm{q}}$ values is observed for quencher $\mathbf{1 0}$ with rectangles I and II. Furthermore, the binding constants $\left(K_{\mathrm{a}}\right)$ calculated from eq 2 for quencher $\mathbf{1 0}$ with $\mathbf{I}-\mathbf{I I I}$ are $2.3 \times 10^{4}, 2.6 \times 10^{2}$, and 6.4 $\times 10^{1} \mathrm{M}^{-1}$, respectively. These values are in good agreement with the values obtained from absorption spectroscopy. Hence rectangle I is a more suitable host than II and III for quencher 10. These results point out that the major contribution of the quenching process of $\mathbf{I}-$ III with $\mathbf{1 0}$ comes from static quenching, i.e., quenching after the formation of an associated complex between the rectangle and the quencher. Lees and co-workers ${ }^{19 b, c}$ studied the quenching behavior of $\operatorname{Re}(\mathrm{I})$-based squares with aromatic compounds and found that square complexes are no different from monomeric $\operatorname{Re}(\mathrm{I})$ complexes. Based on the quenching behaviors of I-III with 10, we conclude that the binding of quenchers with rectangles could lead to more efficient quenching, if the suitable size of rectangles is selected. To understand the effect of $\Delta G^{\circ}$ on the rate constant for the process of ET, $k_{23}$, for the reaction, $\log k_{23}$ is plotted against $-\Delta G^{\circ}$ and the plot is shown in Figure 5. From Figure 5, it is understood that the $k_{23}$ values for different $-\Delta G^{\circ}$ initially increase steeply as $\Delta G^{\circ}$ gradually becomes more negative and then the $k_{23}$ value ultimately levels off at the diffusion-controlled limit at highly negative $\Delta G^{\circ}$. Schanze and MacQueen demonstrated that the highly exothermic back-ET reaction displayed an inverted dependence of the rate of free energy in the $\operatorname{Re}(\mathrm{I})$ donoracceptor complex. ${ }^{35}$ The appearance of the plot in Figure 5 may tempt one to postulate that a Marcus inverted region is observed in this photoinduced ET reaction. The experimentally observed reorganization energy $\lambda_{\text {obs }}$ was estimated to be $0.9 \mathrm{eV}$ by fitting the data in Figure 5. Note that the Marcus inverted region can be observed only if the condition $-\Delta G^{\circ}>\lambda_{\text {obs }}$ is satisfied, which is not the case for the reaction of II and III with 10. A Marcus inverted region (MIR) may be observed when 10 interacts with $\mathbf{I}$, since the $-\Delta G^{\circ}$ value is high $(0.99 \mathrm{~V})$. It is important to note that the reactants must be spherical to apply the Marcus theory. Because the rectangles are not spherical and the $\lambda$ values are close to the $-\Delta G^{\circ}$ values, we can say the system rectangle $\mathbf{I}$ and quencher $\mathbf{1 0}$ is in the threshold of MIR. Thus, a MIR is not observed with rectangles II and III, but in the case of the redox system $\mathbf{I}$ and quencher $\mathbf{1 0}$ the rate constant of ET falls in the threshold of MIR. The alternative explanation for the low $k_{23}$ values observed for rectangles I-III with quencher $\mathbf{1 0}$ at high exoergicity is most likely due to the steric effect of the bulky tetramethyl groups of $\mathbf{1 0}$. To the best of our knowledge, the semiclassical theory of ET has been successfully applied for the first time to photoinduced ET reactions of $\operatorname{Re}(\mathrm{I})$ rectangles with amines. This offers interesting possibilities for the development of photoinduced ET reactions of new supramolecular assemblies with bioactive molecules and for comparing the experimental $k_{\mathrm{q}}$ values with the semiclassical theory of ET.

\section{Conclusion}

The results observed in the present study establish that the ${ }^{3}$ MLCT excited state of $\operatorname{Re}(\mathrm{I})$-based molecular rectangles is efficiently quenched by aromatic amines in dichloromethane solution at room temperature. The transient absorption spectra and luminescence quenching data clearly show that the excited state of $\operatorname{Re}(\mathrm{I})$ rectangles undergoes rapid ET reactions with aromatic amines. The efficiency of quenching rate constants $\left(k_{\mathrm{q}}\right)$ was found to be higher than those for monomeric $\operatorname{Re}(\mathrm{I})$ complexes and $\operatorname{Re}(\mathrm{I})$-based metallocyclophanes. The formation of an amine radical was observed for the first time in the ${ }^{3}$ MLCT excited-state electron-transfer reaction of a $\operatorname{Re}(\mathrm{I})$ rectangle with an amine. The quenching rate constant, $k_{\mathrm{q}}$, remains diffusion-limited at high negative $\Delta G^{\circ}$ values, and the $k_{\mathrm{q}}$ values are nicely correlated with the $\Delta G^{\circ}$ values. In addition, semiclassical theory of ET was successfully applied in the photoluminescence quenching of $\operatorname{Re}(\mathrm{I})$ rectangles with amines.

Acknowledgment. We thank Academia Sinica and the National Science Council of Taiwan for financial support.

Supporting Information Available: Emission spectra and Stern-Volmer plot for the luminescence quenching of rectangle II with quencher 10. This material is available free of charge via the Internet at http://pubs.acs.org.

\section{References and Notes}

(1) (a) Chiapperino, D.; McIlroy, S.; Falvey, D. E. J. Am. Chem. Soc. 2002, 124, 3567. (b) Goto, M.; Otsuka, K.; Chen, X.; Tao, Y.; Oyama, M. J. Phys. Chem. A 2004, 108, 3980.

(2) (a) Stubbe, J.; van der Donk, W. A. Chem. Rev. 1998, 98, 705. (b) Leventis, N.; Yang, J.; Fabrizio, E. F.; Rawashdeh, A. M. M.; Oh, W. S. Sotiriou-Leventis, C. J. Am. Chem. Soc. 2004, 126, 4094.

(3) (a) Fujieda, N.; Satoh, A.; Tsuse, N.; Kano, K.; Ikeda, T. Biochemistry 2004, 43, 10800. (b) Anderson, L. B.; Ouellette, A. J. A. Rye, J. E.; Maderia, M.; MacCoss, M. J.; Yates, J. R., III; Barry, B. A. J. Am. Chem. Soc. 2004, 126, 8399.

(4) (a) Chen, P.; Doweyko, A. M.; Norris, D.; Gu, H. H.; Spergel, S. H.; Das, J.; Moquin, R. V.; Lin, J.; Wityak, J.; Iwanowicz, E. J.; McIntyre, K. W.; Shuster, D. J.; Behnia, K.; Chong, S.; de Fex, H.; Pang, S.; Pitt, S.; Shen, D. R.; Thrall, S.; Stanley, P.; Kocy, O. R.; Witmer, M. R.; Kanner, S. B.; Schieven, G. L.; Barrish, J. C. J. Med. Chem. 2004, 47, 4517. (b) Strømgaard, K.; Mellor, I. Med. Res. Rev. 2004, 24, 589. (c) Krezel, A.; Bal, W. Chem. Res. Toxicol. 2004, 17, 392.

(5) (a) Theys, R. D.; Sosnovsky, G. Chem. Rev. 1997, 97, 83. (b) Bergstrom, S. K.; Edenwall, N.; Laven, M.; Velikyan, I.; Langstrom, B.; Markides, K. E. Anal. Chem. 2005, 77, 938.

(6) Mathias, L. J.; Shemper, B. S.; Alirol, M.; Morizur, J. F. Macromolecules 2004, 37, 3231.

(7) (a) Novak, P.; Muller, K.; Santhanam, K. S. V.; Haas, O. Chem. Rev. 1997, 97, 207. (b) Bandyopadhyay, Pu.; Bandyopadhyay, Pr.; Regen, S. L. Bioconjugate Chem. 2002, 13, 1314.

(8) (a) Kido, J.; Kimura, M.; Nagai, K. Science 1996, 275, 1267. (b) Mochizuki, H.; Hasui, T.; Kawamoto, M.; Ikeda, T.; Adachi, C.; Taniguchi, Y.; Shirota, Y. Macromolecules 2003, 36, 3457.

(9) (a) Imahori, H.; Kimura, M.; Hosomizu, K.; Sato, T.; Ahn, T. K.; Kim, S. K.; Kim, D.; Nishimura, Y.; Yamazaki, I.; Araki, Y.; Ito, O.; Fukuzumi, S. Chem. Eur. J. 2004, 10, 5111. (b) Kruger, J.; Plass, R.; Gratzel, M.; Cameron, P. J.; Peter, L. M. J. Phys. Chem. B 2003, 107, 7536.

(10) (a) Wurthner, F.; Yao, S.; Debaerdemaeker, T.; Wortmann, R. J. Am. Chem. Soc. 2002, 124, 9431. (b) Coe, B. J.; Harris, J. A.; Brunschwig, B. S.; Garin, J.; Orduna, J.; Coles, S. J.; Hursthouse, M. B. J. Am. Chem. Soc. 2004, 126, 10418 .

(11) (a) Balzani, V.; Juris, A. Coord. Chem. Rev. 2001, 211, 97. (b) Armaroli, N. Chem. Soc. Rev. 2001, 30, 113. (c) Chiorboli, C.; Rodgers, M. A. J.; Scandola, F. J. Am. Chem. Soc. 2003, 125, 483. (d) Fleming, C. N.; Dupray, L. M.; Papanikolas, J. M.; Meyer, T. J. J. Phys. Chem. A 2002, 106, 2328. (e) Tung, Y. L.; Wu, P. C.; Liu, C. S.; Chi, Y.; Yu, J. K.; Hu, Y. H.; Chou, P. T.; Peng, S. M.; Lee, G. H.; Tao, Y.; Carty, A. J.; Shu, C. F.; Wu, F. I. Organometallics 2004, 23, 3745. (f) Ranjan, S.; Lin, S. Y.; Hwang, K. C.; Chi, Y.; Ching, W. L.; Liu, C. S.; Tao, Y. T.; Chien, C. H.; Peng, S. M.; Lee, G. H. Inorg. Chem. 2003, 42, 1248.

(12) (a) Ashton, P. R.; Brown, C. L.; Chrystal, E. J. T.; Goodnow, T. T.; Kaifer, A. E.; Parry, K. P.; Slawin, A. M. Z.; Spencer, N.; Stoddart, J. F.; Williams, D. J. Angew. Chem., Int. Ed. Engl. 1991, 30, 1039. (b) Atwood, J. L.; Holman, K. T.; Steed, J. W. J. Chem. Soc., Chem. Commun. 1996. 1401. (c) Collin, J. P.; Gavina, P.; Heitz, V.; Sauvage, J. P. Eur. J. Inorg. Chem. 1998, 1.

(13) (a) Falloon, S. B.; Szafert, S.; Arif, A. M.; Gladysz, J. A. Chem Eur. J. 1998, 4, 1033. (b) Wong, K. M. C.; Lam, S. C. F.; Ko, C. C.; Zhu, N.; Yam, V. W. W.; Roue, S.; Lapinte, C.; Fathallah, S.; Costuas, K.; Kahlal, S.; Halet, J. F. Inorg. Chem. 2003, 42, 7086, and references therein. 
(14) Rajendran, T.; Manimaran, B.; Liao, R. T.; Lin, R. J.; Thanasekaran, P.; Lee, G. H.; Peng, S. M.; Liu, Y. H.; Chang, I. J.; Rajagopal, S.; Lu, K L. Inorg. Chem. 2003, 42, 6388.

(15) (a) Dinolfo, P. H.; Williams, M. E.; Stern, C. L.; Hupp, J. T. J. Am. Chem. Soc. 2004, 126, 12989. (b) Sun, S. S.; Anspach, J. A.; Lees, A. J.; Zavalij, P. Y. Organometallics 2002, 21, 685. (c) Woessner, S. M.; Helms, J. B.; Shen, Y.; Sullivan, B. P. Inorg. Chem. 1998, 37, 5406. (d) $\mathrm{Xu}$, D.; Khin, K. T.; van der Veer, W. E.; Ziller, J. W.; Hong, B. Chem. Eur. J. 2001, 7, 2425. (e) Slone, R. V.; Yoon, D. I.; Calhoun, R. M.; Hupp, J. T. J. Am. Chem. Soc. 1995, 117, 11813. (f) Manimaran, B.; Thanasekaran, P.; Rajendran, T.; Lin, R. J.; Chang, I. J.; Lee, G. H.; Peng, S. M.; Rajagopal, S.; Lu, K. L. Inorg. Chem. 2002, 41, 5323.

(16) (a) Yam, V. W. W.; Lau, V. C. Y.; Cheung, K. K. Organometallics 1996, 15, 1740. (b) Mayr, A.; Yu, M. P. Y.; Yam, V. W. W. J. Am. Chem. Soc. 1999, 121, 1760. (c) Hong, B.; Ortega, J. V. Angew. Chem., Int. Ed. 1998, 37, 2131.

(17) (a) Thanasekaran, P.; Liao, R. T.; Liu, Y. H.; Rajendran, T.; Rajagopal, S.; Lu, K. L. Coord. Chem. Rev. 2005, 249, 1085. (b) Slone, R. V.; Benkstein, K. D.; Belanger, S.; Hupp, J. T.; Guzei, I. A.; Rheingold, A. L. Coord. Chem. Rev. 1998, 171, 221.

(18) Ceroni, P.; Credi, A.; Balzani, V.; Campagna, S.; Hanan, G. S.; Arana, C. R.; Lehn, J. M. Eur. J. Inorg. Chem. 1999, 1409.

(19) (a) Benkstein, K. D.; Hupp, J. T.; Stern, C. L. Angew. Chem., Int. Ed. 2000, 39, 2891. (b) Sun, S. S.; Lees, A. J. J. Am. Chem. Soc. 2000, 122, 8956. (c) Sun, S. S.; Lees, A. J. Coord. Chem. Rev. 2002, 230, 171.

(20) (a) Luong, J. C.; Nadjo, L.; Wrighton, M. S. J. Am. Chem. Soc. 1978, 100, 5790. (b) Gan, H.; Zhao, X.; Whitten, D. G. J. Am. Chem. Soc 1991, 113, 9409. (c) Ito, T.; Rokita, S. E. J. Am. Chem. Soc. 2004, 126, 15552. (d) Pischel, U.; Zhang, X.; Hellrung, B.; Haselbach, E.; Muller, P. A.; Nau, W. M. J. Am. Chem. Soc. 2000, 122, 2027.

(21) (a) Lin, J. T.; Sun, S. S.; Wu, J. J.; Lee, L.; Lin, K. J.; Huang, Y. F. Inorg. Chem. 1995, 34, 2323. (b) Ciana, L. D.; Haim, A. J. Heterocycl. Chem. 1984, 21, 607. (c) Champness, N. R.; Khlobystov, A. N.; Majuga, A. G.; Schroder, M.: Zyk, N. V. Tetrahedron Lett. 1999, 40, 5413.
(22) Wu, P. C.; Yu, J. K.; Song, Y. H.; Chi, Y.; Chou, P. T.; Peng, S. M.; Lee, G. H. Organometallics 2003, 22, 4938.

(23) (a) Sun, S. S.; Robson, E.; Dunwoody, N.; Silva, A. S.; Brinn, I. M.; Lees, A. J. Chem. Commun. 2000, 201. (b) Baba, A. I.; Shaw, J. R.; Simon, J. A.; Thummel, R. P.; Schmehl, R. H. Coord. Chem. Rev. 1998, $171,43$.

(24) Thanasekaran, P.; Rajendran, T.; Rajagopal, S.; Srinivasan, C.; Ramaraj, R.; Ramamurthy, P.; Venkatachalapathy, B. J. Phys. Chem. A 1997, 101, 8195 .

(25) (a) Kitamura, N.; Obata, R.; Kim, H. B.; Tazuke, S. J. Phys. Chem. 1987, 91, 2033. (b) Nad, S.; Pal, H. J. Phys. Chem. A 2000, 104, 673.

(26) Darmanyan, A. P.; Lee, W.; Jenks, W. S. J. Phys. Chem. A 1999, $103,2705$.

(27) Wrighton, M. S.; Morse, D. L. J. Am. Chem. Soc. 1974, 96, 998.

(28) (a) Kalyanasundaram, K. J. Chem. Soc., Faraday Trans. 2 1986, 82, 2401. (b) Burke, M. R.; Brown, T. L. J. Am. Chem. Soc. 1989, 111, 5185. (c) Feliz, M.; Ferraudi, G.; Altmiller, J. J. Phys. Chem. 1992, 96, 257.

(29) (a) Tapolsky, G.; Duesing, R.; Meyer, T. J. Inorg. Chem. 1990, 29, 2285. (b) Tapolsky, G.; Duesing, R.; Meyer, T. J. J. Phys. Chem. 1989, 93,3885 .

(30) (a) Devadoss, C.; Fessenden, R. W. J. Phys. Chem. 1991, 95, 7253 (b) Arimitsu, S.; Masuhara, H.; Mataga, N.; Tsubomura, H. J. Phys. Chem. 1975, 79, 1255 .

(31) (a) Rehm, D.; Weller, A. Isr. J. Chem. 1970, 8, 259. (b) Rehm, D.; Weller, A. Ber. Bunsen-Ges. Phys. Chem. 1969, 73, 834.

(32) (a) Smoluchowski, M. Z. Phys. Chem. 1917, 92, 129. (b) Keizer, J. Chem. Rev. 1987, 87, 167.

(33) Fuoss, R. M. J. Am. Chem. Soc. 1958, 80, 5059.

(34) Kavarnos, G. J.; Turro, N. J. Chem. Rev. 1986, 86, 401.

(35) MacQueen, D. B.; Schanze, K. S. J. Am. Chem. Soc. 1991, 113 